\title{
Is Increased Ideological Distance From One's Congresspeople Associated With Increased Self-Identification as an Independent?
}

\author{
Bradley Mankoff \\ University of California Los Angeles
}

While much research studies what political attitudes and political behaviors distinguish American nonpartisans ("Independents") from partisans, little research has investigated what environmental factors in an individual's life are associated with self-identification as an Independent. This paper begins that investigation by testing whether a rudimentary measure of distance of oneself from one's congresspeople is positively associated with one's probability of self-identifying as an Independent. Seminal research from social psychology about the availability heuristic and social desirability bias combined with Klar's and Krupnikov's insights about a general aversion to partisan labels provide the theoretical framework for my hypothesis. Individuals' ideologies are taken from self-reports from the CCES cumulative file ( 424,000 respondents), and congresspersons' ideologies are taken from DW-NOMINATE. I find a modest positive association between distance and independent-identity, however the inconsistency of that result across different ideologies and across the House and Senate leads me to doubt the substantive significance of my findings. A panel study or experiment could better test my hypothesis.

Keywords: partisan identification, nonpartisanship, independent-identity, social identity theory, availability heuristic, social desirability bias

\section{INTRODUCTION}

Scholars have made significant headway toward understanding rising polarity in the US Congress (Ansolabehere, Snyder, \& Stewart, 2001; Lee, Moretti, \& Butler, 2004; Hill \& Tausanovitch, 2015) and rising affectual polarity among the populace (Iyengar, Sood, \& Lelkes, 2012; Iyengar and Westwood, 2015; Levendusky \& Malhotra, 2015; Caughey, Dunham, \& Warshaw, 2016; Ahler \& Sood, 2018; Iyengar, Lelkes, Levendusky, Malhotra, \& Westwood, 2019), researchers tend to ignore the group of citizens whose attitudes and behaviors are not described by those trends in partisan polarity- "independents." The juxtaposition between the small volume of contemporary research focused on independents and the large (Pew, 2019; Twenge, Honeycutt, Prislin, \& Sherman, 2016) and possibly growing (APPC, 2014; Twenge et al., 2016) proportion of independents motivates this research.

A set of results from the book Independent Politics by Klar and Krupnikov (2016) suggests a new angle from which we should study nonpartisans. Klar and Krupnikov demonstrate that the label "independent" is more socially desirable than the labels "Republican" and "Democrat". Twenge et al. (2016) show that from 1972 to 2014, the proportion of self-described ideological moderates declined while the proportion of selfdescribed independents increased. If party labels were more desirable in the 1970s and 1980s than they are 
today, the transition toward the present state of undesirable party labels could explain the increase in independent-identity despite a decrease in self-described moderate-status. While this study does not address this causal question directly, it does take a cross-sectional approach to test whether one operationalization of the social desirability of party labels - the extremity of one's elected officials in Congress as measured by DW-NOMINATE - can explain any of the variation in independent-identity across individuals. Specifically, I will try to predict individuals' probabilities of self-identification as an independent as a function of the unidimensional, ideological distance between that individual and his or her House Representative and two Senators, respectively.

I will elaborate extensively on this operationalization later in this paper, but the basic logic is as follows. There is a large literature demonstrating high levels of affective polarity in the public today. Klar and Krupnikov connect this literature to partisan identification by showing, through experiments, that negative affect toward the parties is often motivated by observations and/or experiences of polarity themselves. Thus, in light of these phenomena, I expect a greater probability of independent-identity from people who have greater levels of negative affect toward the parties. Lastly, tying these expectations in to Congress, I expect that people represented by more extreme members of congress have greater exposure to polarity (not tested here), have greater negative affect toward party labels (not tested here), and thus will be more likely to selfidentify as independents (tested in this paper). In the literature review that follows, I will present evidence from social identity theory and elsewhere that supports the untested links in the above logical chain.

The paper proceeds as follows. First, I review the literatures relevant to my claims. Second, I discuss the operationalization of my data in light of that research and will formulate a research hypothesis relating that operationalization to independent-identification. Third, I discuss the probit regression analysis which I use to test my hypothesis. Fourth, I discuss the results of that test. Fifth and in conclusion, I will discuss these results in the context of previous research as well as opportunities for future research.

\section{LITERATURE REVIEW}

\section{Economic Voting}

To frame my utilization of the "distance" concept in A political context I rely on Downs's theory of Economic Voting (1957). Downs changed the study of the voter in politics by applying utility functions from microeconomics to a prospective voter's decisions about whether to vote and for whom to vote. His model awards more utility to the prospective voter if that individual's preferred candidate takes office. An individual's preferred candidate is the one who is located closest to that individual on the familiar unidimensional ideological scale that runs from liberal (larger, more interventionist government) to conservative (smaller, less interventionist government). The gap between oneself and a candidate is termed a "distance," and prospective voters, if they vote at all, are expected to vote for the candidate with the smallest distance from themselves. The individual's perception that voting for her preferred candidate will increase the probability of that candidate winning, Downs argues, motivates some individuals to vote. For other prospective voters, Downs suggests, it may be the mere psychic benefit associated with voting for one's preferred candidate, not a perceived connection between voting and obtaining desired political outcomes, that motivates these prospective voters. Regardless of the mechanism driving voting decisions in the economic voting model, the model tells us to expect distance to be inversely correlated with turnout and vote-choice. In this paper, I test whether distance is associated not with individuals' vote-choices but rather their party-identifications. I expect that individuals who are at greater distances from their most prominent elected officials (not including officials who are shared by everybody else in the sample such as the President, Speaker of the House, or Senate Majority Leader) are more likely than individuals who are at lesser distances from these officials to self-identify as independents (Downs, 1957).

\section{Party Identification}

Second, I offer an overview of the literature on partisan identification and its implications for independent-identification. The American Voter by Campbell, Converse, Miller, and Stokes (1960) argues that party-identification is a psychological attachment to a group much like how religious- or racial-identity 
is a psychological attachment to a religious or racial group. Further, they argue, one's partisan-identity is largely "inherited" from one's other group memberships. If most people in your racial group identify as members of one party (such as Black Americans in the Democratic party today), you are very likely to selfidentify as a member of that party as well. If most people in your religious group identify as members of one party (such as Evangelical Christians in the Republican party today), you are very likely to self-identify as a member of that party as well. And if both of one's parents are active members of (i.e. vote for, volunteer for, donate to, etc.) the same major political party while one is growing up, one is very likely to begin adulthood identifying with that same party. The American Voter makes no assumptions about Independents. Instead, it acknowledges that some self-described Independents are indicating their "lack of positive attraction to one of the parties" while others may be "repelled by the parties or by partisanship itself and value their position as Independents" (Campbell et al., 1960, p.123). While Campbell et al. acknowledge that those who self-identify as Independents for different reasons are likely to have different feelings and voting behaviors from each other regarding the two parties, the authors group these Independents together for the purpose of their analyses.

\section{Social Psychology and Its Application to Independents}

In the 1970s, Tajfel and Turner introduced Social Identity Theory to describe how individuals see themselves as members of groups and how one's group memberships affect how one thinks about and interacts with other people (Tajfel \& Turner, 1979). Later, researchers began to apply the principles of Social Identity Theory to partisan groups (Greene, 1999; Green, Palmquist, \& Schickler, 2002). Green, Palmquist, and Schickler suggest that people determine their partisan identities by asking themselves "What kinds of social groups come to mind as I think about Democrats, Republicans, and Independents? Which assemblage of groups (if any) best describes me" (Green, Palmquist \& Schickler, 2002, p. 8). This research serves as the seed for Klar's and Krupnikov's studies of independents and party labels.

Klar and Krupnikov, in their 2016 book Independent Politics, show that many Americans have come to believe that there is something socially undesirable about identifying with either of the two parties. Further, through experiments they show the relative social appeal of political independence (Klar \& Krupnikov, 2016). Informed by Social Identity Theory, they argue that "Motivated by a need to make a positive impression in the face of partisan disagreement, people shy away from undertaking social political actions that outwardly display their partisan preferences" (Klar \& Krupnikov, p. 169-170). They argue that even survey responses qualify as such outward displays. They also argue that this undesirability of identifying as a partisan is motivated by the polarization reviewed in the introduction of this paper. Research on social desirability biases - the general tendency among survey respondents to select the response-option that they expect is desired by the researchers - corroborates Klar's and Krupnikov's expectation (Allen, 1953). Thus, Klar and Krupnikov argue that much of the independent-identification observed on surveys is merely an expression of this motivation to make a positive impression against a backdrop of commonly held negative affect at least toward out-partisans and in many cases toward all partisans. I argue that it is reasonable to assume that this motivation is stronger when individuals have more extreme partisans on the tops of their minds (Zaller, 1992). I will now turn to a brief discussion of the availability heuristic to support my assumption.

The availability heuristic is one of the heuristics or biases (mental shortcuts) identified by social psychologists Kahneman and Tversky in the 1970s as commonly employed by most people. The researchers show through experiments that people tend to judge examples that they recall more easily as being more common than examples that they struggle to recall (Tversky \& Kahneman, 1974). People can easily recall the President when thinking about partisans. Thus, for example, the availability heuristic suggests that people will tend to over-estimate the presence of the President's traits among partisans generally.

Returning now to the context of this study, image a survey respondent at the moment that she is being asked to self-identify as a Democrat, Republican, or Independent. First, as Green et al. suggest, she may ask herself "What kinds of social groups come to mind as I think about Democrats, Republicans, and Independents?" In employing the availability heuristic, she may call up the most easily available mental images of members of those groups. Succumbing to the social desirability bias, she may assess the social 
desirability of associating oneself with the recalled members of Congress (MCs) by identifying with the same party as one of them. The first politician she is likely to imagine is the President. While focusing on this most famous, "available" elected official could be interesting in a time-series analysis in which those officials change over time, the lack of variation in who one's President is at a given moment (everybody at a given time has the same President) precludes my use in this cross-sectional study of this and other offices that lack within-time, across-space variation. Thus, to ensure that the survey respondents I analyze vary in which politicians they imagine, I assume that at some point in this application of the availability heuristic and social desirability bias, some respondents imagine their own House Representative and two Senators (henceforth "local MCs"). In imagining their local MCs, those whose local MCs are more extreme are, according to the availability heuristic, more likely than those whose local MCs are less extreme to have an exaggerated perspective on how extreme American politicians are generally. If Klar and Krupnikov are right that aversion to partisan labels and partisans generally is largely caused by the present state of high polarity in Congress, social desirability bias should be especially impactful for somebody represented by one of the MCs who is more emblematic of today's high polarity, thus causing a respondent represented by those MCs to view partisan labels as less desirable and the independent label as more desirable (relative to respondents who are not represented by relatively extreme MCs). Thus, respondents represented by more extreme local MCs should tend to self-identify as independents more than respondents represented by less extreme local MCs.

Surely, some respondents won't consider these officials (or perhaps any officials) at all. In the absence of an experimental design, I cannot ensure, let alone manipulate, anything about the respondents' mental processes. Thus, any effect I identify across the entire sample should be small as I average predicted null effects with predicted effects. Further, any associations should not be interpreted as causal effects. Rather, they are merely associations in the data that, based on the psychological theories reviewed above, could plausibly be discussed in a causal context if a researcher employed a design allowing for causal inference such as the use of panel data or an experiment.

In summary, first, Downsian economic voting gives me the notion of "distance," which I operationalize later in this paper. Second and crucially, Klar and Krupnikov show a social desirability bias that leads many people to prefer self-identification as an independent over self-identification as a partisan. This research suggests that polarization and associated disagreement and confrontation between prominent members of the two major parties drives negative perceptions of partisans and, accordingly, less negative perceptions of independents. The resulting relative social desirability of independent-identity drives more independentidentification than we would expect in a world with lower polarity. Further, I argue that the availability heuristic suggests that those represented by more extreme officials relative to those represented by less extreme officials tend to believe that partisans generally are extreme like their local MCs are. This may lead to a positive association between the extremity of one's local MCs and one's probability of self-identifying as an independent. Next, I turn to a discussion of how I will operationalize distance using data.

\section{DATA, OPERATIONALIZATION, \& HYPOTHESIS}

To calculate the distance between a respondent and her local MCs, I need measures of the ideologies of respondents and MCs. For the MCs, I use first-dimension scores emerging from the NOMINATE procedure that bases its measures on MCs' roll-call votes as Congresspeople (Poole \& Rosenthal, 1985; Poole, 2005; Poole \& Rosenthal, 2011; Lewis, Poole, Rosenthal, Boche, Rudkin, \& Sonnet, 2021). These scores are highly correlated with the MCs' partisan-identifications. For the respondents, I use their selfreported ideology from the Cooperative Congressional Election Study (CCES) survey (Kuriwaki, 2018). This ideology can be: "Very Liberal", "Liberal", "Moderate", "Conservative", or "Very Conservative." The cumulative file for this survey contains about 424,000 unique respondents, and there is a corresponding congressional district for each respondent, which I use to link respondents to their MCs. The CCES data includes a significant number of missing values for variables used in my model. I discuss missingness in the Appendix. While methods exist to calculate a survey respondent's ideology based on the political attitudes they express on surveys (Fowler et al., 2020), the ideological scores that emerge-not observable 
by the respondent herself - may not be ideal for my purposes. Since I am suggesting that individuals' perceptions of the distances between themselves and their local MCs may be associated with independentidentification while responding to surveys, a measure that is more likely to be on the "top of the mind" of the respondents may be more appropriate than a measure that is unobserved by the respondent and calculated by a researcher (Kahneman \& Tversky, 1974; Zaller, 1992).

To calculate the distance measures, I scale the measures of respondents' and MCs' ideologies to range from 0 to 1. I create three measures of distance-one for the House Rep. and one each for the two Senators - by taking the absolute value of the difference between the individual's and the MC's scaled ideology. Because my measure for individuals is very coarse $(0, .25, .5, .75$, and $1 ; 0=$ "Very Liberal") while my measure for MCs is continuous (0 to 1), my measure of distance is continuous but "lumpy," showing peaks and valleys that lack correspondence to meaningful phenomena in the minds of the respondents or political reality. The following histogram overlays the distance measures, showing the number of respondents in each range of distance measures (Figure 1).

\section{FIGURE 1 \\ HISTOGRAM OF ALL THREE DISTANCES MEASURES}

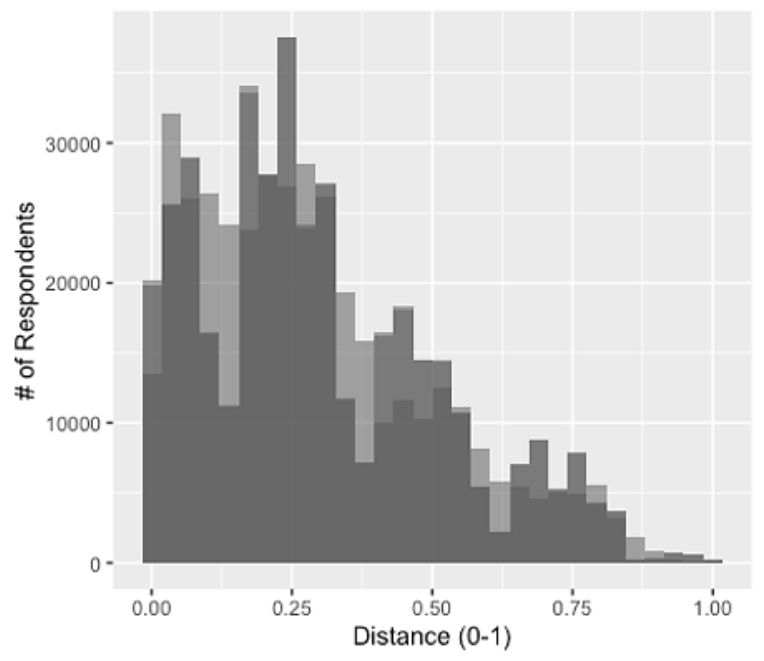

The important takeaway from this set of histograms is that, indeed, my measure of distance is coarse. Instead of observing a smooth distribution of scores as we would like from a continuous independent variable, we observe peaks and valleys that follow the coarseness of the individual-measure of ideology. This is the main reason to prefer a continuous measure of individual-ideology coded by the researchers, but by subsetting respondents according to their coarse ideologies and looking at the relationship between distance and independent-identification within each cohort of respondent-ideology, I avoid concerns about coarseness of this main independent variable. These concerns are still meaningful for the regression analysis.

Before discussing Figure 2 and introducing my central hypothesis, I must review an important caveat. If your ideology is on the opposite side of the spectrum relative to your MC (you are a liberal and your MC is a conservative, for example), I expect increased out-party identity cut across my expectation of increased independent-identity. Thus, I subset the data in the graphs in Figure 2 to include only those who share an ideological direction with each MC respectively (only those respondents who are "matched"). For the regression, I interact the distance variables with their respective "match" variables. Moderates are coded as $1 \mathrm{~s}$ for the match variables because I always expect increased distance from a moderate to be associated with a greater probability of independent-identity. Thus, all moderates are included in the graphs. Hence emerges my central hypothesis: 
H1: Given shared ideological direction with one's MC, greater distances from that MC to the individual should be associated with a greater predicted probability that the individual self-identifies as an independent.

Each row in Figure 2 pertains to a different group of respondents. In the top row, for example, all three plots pertain to those who self-identify as "Very Liberal." Each column in Figure 2 pertains to a different elected official. The left column pertains to House Representatives while the middle and right columns pertain to Senators. Which Senator counts as "Senator 1" or "Senator 2" is randomized for each respondent, so we expect plots in columns 2 and 3 to be nearly identical (as well as coefficients on the "Senator" variables in the regression analysis). The respondents in the three plots in each row (except for moderates in the third row) are not exactly the same respondents because some share an ideological direction with one of their MCs but not with another. A respondent identifying as "Very Liberal" and who has a liberal House Representative, one liberal Senator, and one conservative Senator is included in only two out of the three plots on the first row-the one pertaining to the House Representative and only one of the two plots pertaining to Senators. The vertical line in each plot is drawn where distance is equal to zero for that set of respondents. Crucially, respondents in each plot share a self-described ideology. The blue lines are smoothed estimates of the proportion of independents for each value of distance. For this plot, I use raw distances, not their absolute values, so that I can observe direction-specific differences. One may suggest that the "Very Liberal" and "Liberal" as well as "Very Conservative" and "Conservative" respondents should be grouped together in order to decrease the width of the confidence intervals in Figure 2 below. This procedure would undermine the interpretability of the plots because while the "Very Liberal" respondents can only be out-flanked to the right, the "Liberal" respondents can be out-flanked to either direction. One may also suggest that if I want to keep respondents separated according to their five-pointideology, I could reduce the width of confidence intervals by collapsing the House and Senate data together or at least collapsing the data for both Senators together. This procedure would also undermine the interpretability of the plots, as the following example illustrates. Imagine a moderate who is represented by an extremely liberal Senator and an extremely conservative Senator. My hypothesis predicts that this individual is more likely than if he were represented by moderate Senators to self-identify as an Independent. However if I collapsed data for both Senators together, this respondent's average distance for the two Senators will likely be close to zero. Because I want to be able to distinguish between moderates represented by moderates (who ought to be coded as having distances near zero) and individuals as described above, I do not aggregate distances from multiple representatives into the same plots.

Next, I embed a preliminary test of the plausibility of the mechanism I propose to explain why I expect increased distance to be associated with increased independent-identity. My proposed mechanism relies on a survey-respondent being aware of who her representatives are and where those representatives are located on a unidimensional ideological scale relative to the respondent herself. I assume that those who claim to follow the news more often are more likely to have this knowledge. Further, I expect that those who claim that they follow the news "only now and then" or "hardly at all" do not know where their representatives stand relative to themselves and may not even know who those representatives are in the first place. Thus, by only including those with more-frequent claimed news-following-habits in Figure 2, Figure 2 serves as a charitable plausibility test for this project. That is, if Figure 2 does not demonstrate the expected association, it is unlikely that the association exists.

From $\mathrm{H} 1$ hence emerges my expectation for Figure 2: If (given matched ideological direction and a somewhat frequent news-following) greater distance is associated with a greater probability of independentidentity, then each plot should have its trough close to the vertical line. 


\section{FIGURE 2 \\ PROPORTION OF INDEPENDENTS ACROSS VALUES OF DISTANCE FROM HOUSE REP. AND BOTH SENATORS}
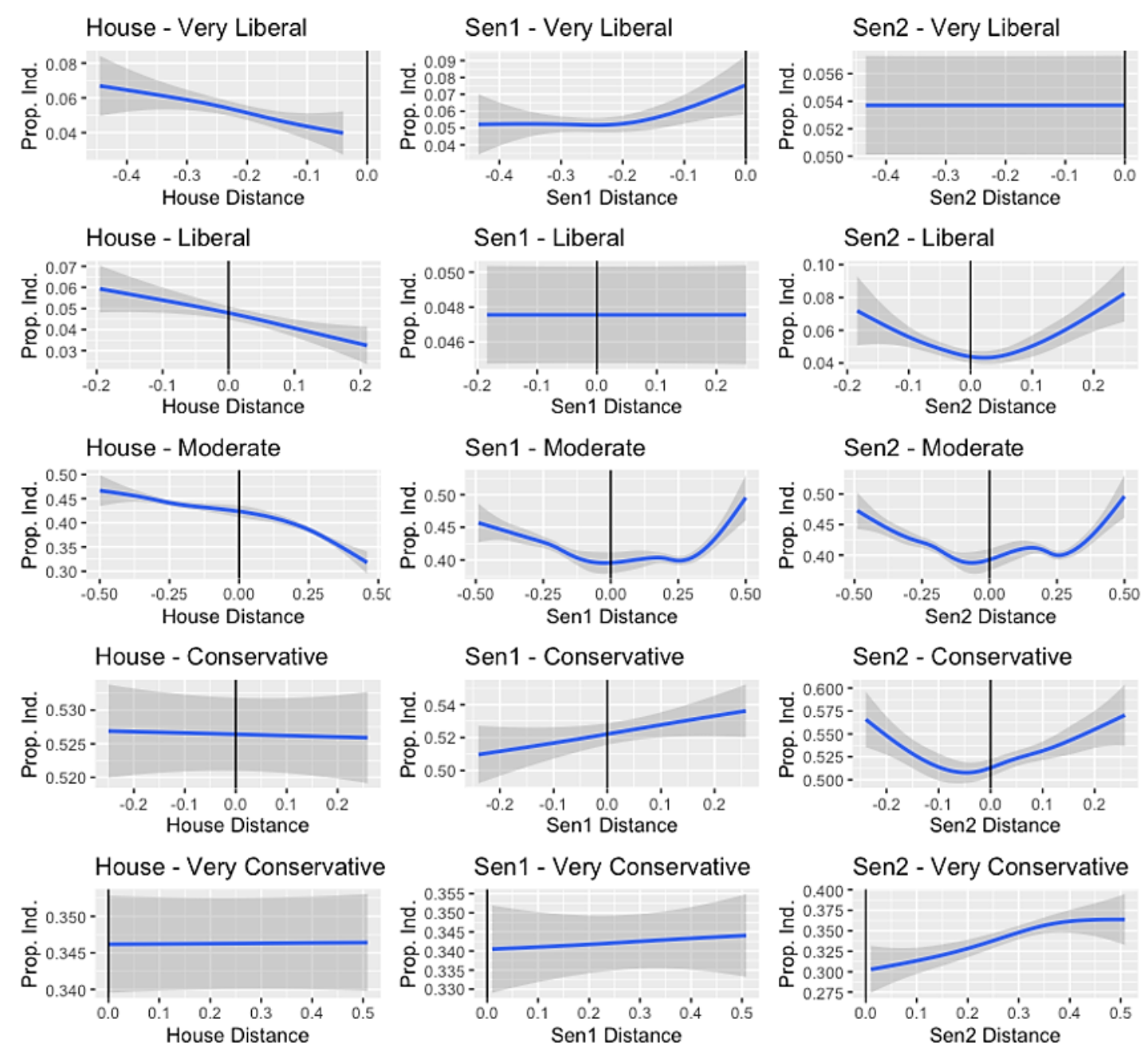

All vertical lines at Distance $=0$; Only matched respondents who follow the news a significant amount

These plots yield extremely mixed inferences. Only the plot in the third row and first column pertaining to moderates and their distances from their respective House Representatives provides strong evidence against my hypothesis. While the other plots are either inconclusive or support my hypothesis, the plot in row three and column one shows that, for my sample, moderates represented by liberal House Representatives are less likely to self-identify as independents than moderates represented by conservative House Representatives. This is an indication that an analysis like mine that largely ignores party-differences is missing an important part of the picture. It suggests that moderates have greater aversion to the Republican party (the one that houses all conservative MCs over the period covered by this dataset) than to the Democratic party. The scales on the y-axes of the different plots tell another part of the asymmetric portion of this story. Liberals represented by liberals (and who generally follow the news) have extremely low base rates of independent-identity (2-10\%) whereas conservatives represented by conservatives (and who generally follow the news) have extremely high base rates of independent-identity (49-60\%). I do not attempt to explain this phenomenon in this paper. Lastly, moderates self-identify as Independents about $40 \%$ of the time, but this figure is closer to $50 \%$ when those moderates are represented by extremely liberal 
or conservative Senators. I also do not attempt to explain why the extremity of Senators but not House Representatives appears to be associated with increased independent-identity for moderates.

One may argue that a moderate represented by a liberal is more liberal on average than a moderate represented by a conservative (and vice versa), but this potential endogeneity works against my hypothesis, not for it. If this endogeneity is present and significant, it would "flatten" the u-shaped curves in columns 2 and 3 of row 3 of the above plot - the plots corresponding to distances from Senators for Moderates. The fact that moderates are more likely to self-identify as independents when their Senators are further away from them shows that my hypothesis is likely to withstand this potential endogeneity insofar as it is present and impactful.

The results from these plots suggest that a relationship exists between distance and the proportion of respondents with independent-identity.

\section{MODEL \& ANALYSIS}

To test whether the effect observed from the array of plots above is observable when the data are aggregated rather than subsetted by ideology, I use a regression-approach. The model attempts to predict individuals' probabilities of independent-identity from the three distances from that individual to her House Representative and two Senators. I interact these distance measures with the dummy "match" variable indicating whether the individual shares the same ideological direction as whichever MC is represented by that distance measure (so three "match" variables, one for each of the three distances measures). This dummy variable should take the value "1" where I expect increased distances to be associated with increased probabilities of independent-identity. This is my expectation wherever self-described ideologues share an ideological direction with their MC because if one did not share an ideological direction with an $\mathrm{MC}$, increased distance from that MC could be associated not only with decreased identification with that MC's party but also increased identification with the out-party. Thus, the expected impact on independentidentity is unclear in those cases.

\section{The Model}

$\operatorname{Pr}\left(Y_{i} \mid X_{i}\right)=\Phi\left(\beta i, j\right.$, Dist . $X_{i, j, \text { Dist. }}+\beta_{i, j, \text { Match }} X_{i, j, \text { Match }}+i, j$, Int . $\left.X_{i, j, \text { Dist. }} X_{i, j, \text { Match }}+\epsilon_{i}\right)$

Because my outcome variable, independent-identity, is dichotomous, a generalized linear model with a probit link function is appropriate. Predicted probabilities of $\mathrm{Y}$ (where $\mathrm{Y}$ is the situation in which an individual self-identifies as an independent) for individual $i$ given covariate values $\mathrm{X}$ are a function of distance measures for each $\mathrm{MC} j$, dummy match variables for each $\mathrm{MC} j$, and the interaction of each distance for $j$ with the appropriate match variable for $j$.

\section{Fixed Effects}

I use fixed effects for year and congressional district in my model because there is significant variation in the proportion of self-identified independents across both years and congressional districts in the CCES

sample. This variation is observable in the below visualizations. First, consider variation across years in Figure 3. 


\section{FIGURE 3 \\ Pr (INDEPENDENTS) IN CCES OVER TIME}

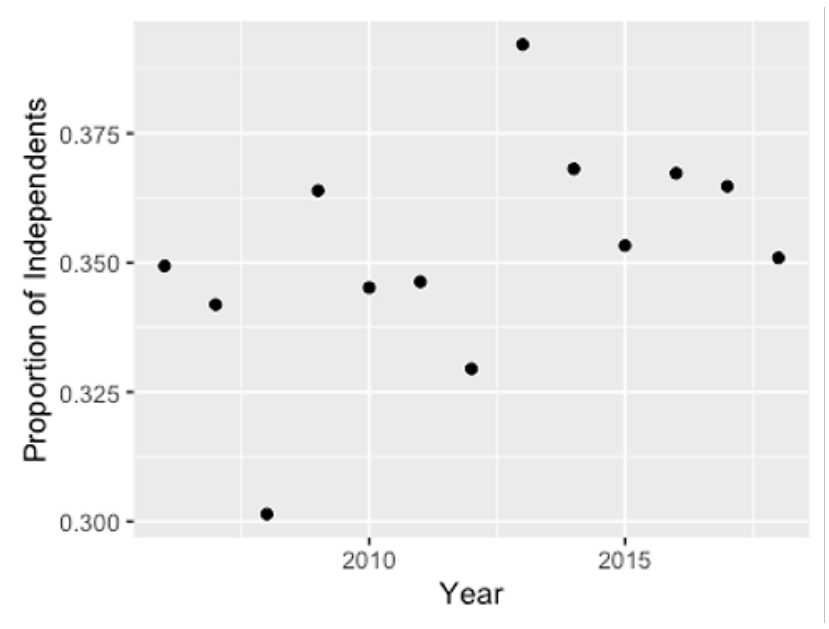

Figure 3 shows how the proportion of independents in the CCES sample varies according to year from a low of about $30 \%$ in 2008 to a high of about $39 \%$ in 2013 . Accounting for this over-time variation by including year-fixed-effects in the model prevents the possibility that effects predicted by the model are in fact only due to variation in independent-identity by year that is irrelevant to my model.

The same logic applies to my decision to use congressional-district-fixed-effects. First, consider the map of states colored according to their proportion of independents across the entire timespan of the CCES sample (2006-2018) in Figure 4. In the map, lighter colors indicate higher proportions of independents while darker colors indicate lower proportions of independents. States range in their proportion of independents from $28.5 \%$ in Democrat-dominated Maryland to $48 \%$ in Idaho.

FIGURE 4

\section{PROPORTION OF RESPONDENTS WHO IDENTIFY AS INDEPENDENTS}

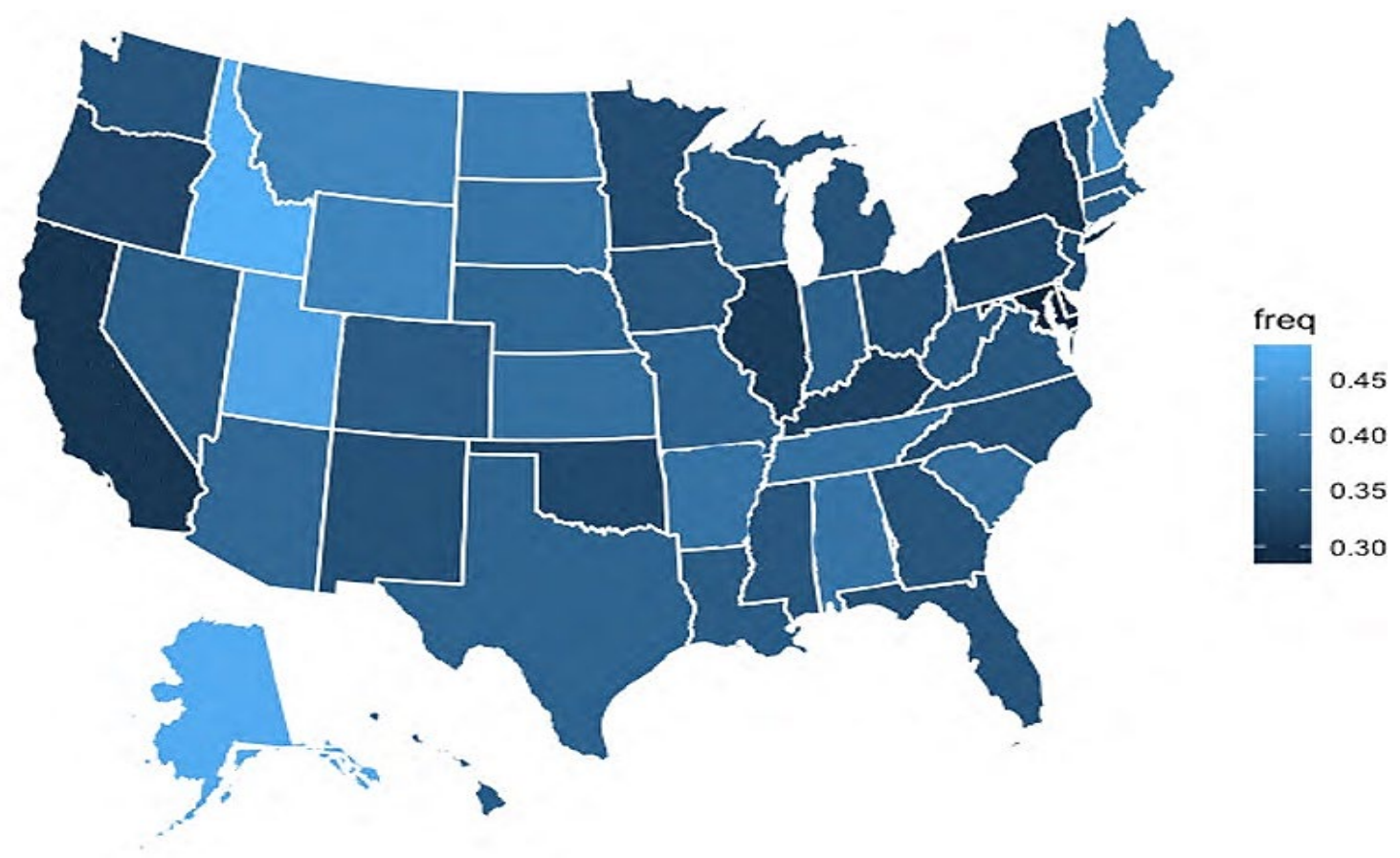


I do not think that this across-state variation is attributable to variation in my distance measures. Rather, I expect this variation is due to variation across a large set of relevant factors, many of which are not present in my data such as the historical presence of urban political machines and other historical factors. Figure 5 shows this variation across congressional districts.

\section{FIGURE 5 \\ HISTOGRAM CDS BY Pr (INDEPENDENTS)}

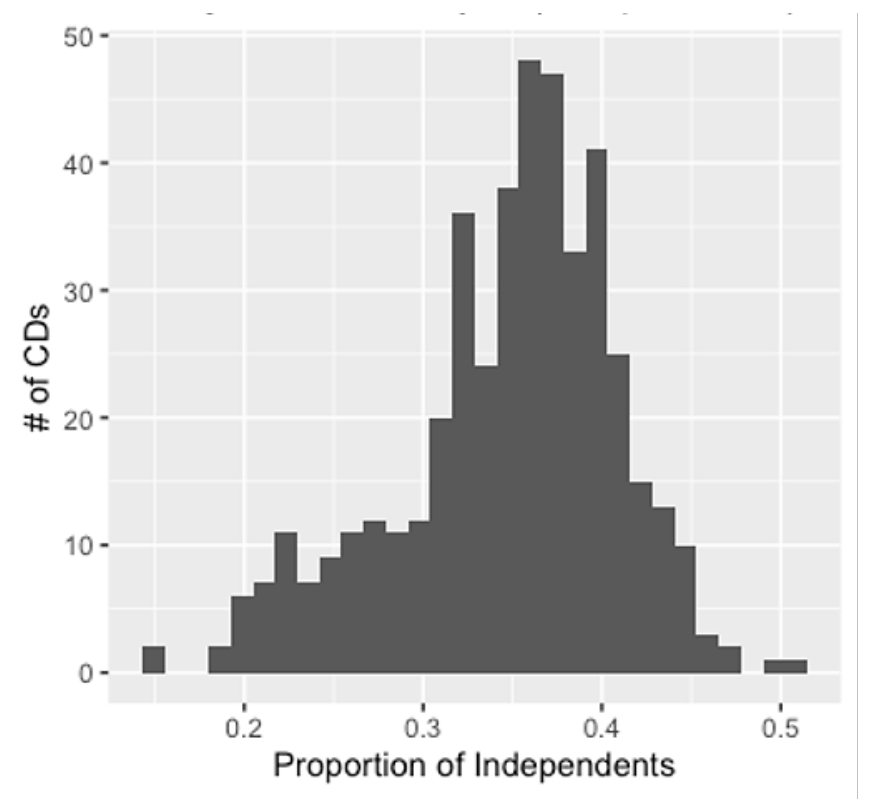

Naturally, congressional districts (again from 2006-2018) show even greater variation in independentidentity than do states. Specifically, many congressional districts have fewer than $30 \%$ of their respondents in the CCES sample self-identify as independents. While some of this variation is associated with variation in my distance variables, much of it is surely, as with states, associated with historical factors unaccounted for in CCES data.

\section{RESULTS}

The results from three different versions of this model - one without any controls, one with basic controls but no fixed effects, and one with controls and fixed effects for year and congressional districtare displayed in Table 1 below. All variables are scaled to run from 0 to 1 . The "Full Model" and "No Fixed Effects" models control for the following: race, sex, age, education, income, interest in the news, whether you have a partner, and retrospective economic evaluation. The "Full Model" also includes fixed effects for year and congressional district. While estimated coefficients are slightly affected by the decision to include fixed effects, all estimated coefficients for explanatory variables of interest retain their sign and significance regardless of whether fixed effects are included. 


\section{TABLE 1}

PREDICTING IND-ID WITH FULL MODEL, MODEL WITHOUT FIXED EFFECTS, AND MODEL CONTROLS

\begin{tabular}{lccc}
\hline & Full Model & No Fixed Effects & No Contils \\
\hline Distance to Rep & $-0.019^{*}$ & -0.271 & -0.422 \\
& $(0.044)$ & $(0.041)$ & $(0.035)$ \\
Rep Match & $0.106^{* * *}$ & 0.036 & -0.016 \\
& $(0.024)$ & $(0.023)$ & $(0.020)$ \\
Distance to Sen1 & $-0.733^{* * *}$ & $-0.597 * * *$ & $-0.452 * * *$ \\
& $(0.040)$ & $(0.039)$ & $(0.019)$ \\
Sen 1 Match & $-0.530^{* * *}$ & $-0.468^{* * *}$ & -0.399 \\
& $(0.022)$ & $(0.021)$ & $(0.019)$ \\
Distance to Sen2 & $-0.579 * * *$ & $-0.504 * * *$ & $-0.419 * * *$ \\
& $(0.022)$ & $(0.021)$ & $(0.019)$ \\
Rep Interaction & $0.580^{* * *}$ & 0.543 & $0.444 * * *$ \\
& $(0.045)$ & $(0.021)$ & $(0.038)$ \\
Sen1 Interaction & $1.125 * * *$ & $1.092 * * *$ & $0.959 * * *$ \\
& $(0.043)$ & $(0.043)$ & $(0.037)$ \\
Sen2 Interaction & $1.183 * * *$ & $1.123 * * *$ & $0.986 * * *$ \\
& $(0.043)$ & $(0.043)$ & $(0.037)$ \\
Constant & $0.542^{* * *}$ & 0.556 & $0.255^{* * *}$ \\
& $(0.074)$ & $(0.028)$ & $(0.022)$ \\
\hline Observations & 306,193 & 306,193 & 384,645 \\
Log Likelihood & $-179,488.400$ & $-182,548.500$ & $-243,943.200$ \\
Akaike Inf. Crit. & $358,938.700$ & $365,144.900$ & $487,906.500$ \\
\hline Note: & & $* \mathrm{p}<0.1 ; * * \mathrm{p}<0.05 ; * * * \mathrm{p}<0.01$
\end{tabular}

The regression analyzes summarized in Table 1 shows the relationship between distance and independent-identity interacted with my "match" dummy variables. For Table 2, I display the results of the "Full Model" from above alongside an identical model that also interacts the "News interest" variable with each of my three original interaction variables. This allows me to test the extent to which my main interaction variables vary in their impact according to the respondent's familiarity with current events. Hence emerges my final hypothesis:

H2: If following the news moderates my proposed mechanism, then the coefficients on the "News" interaction terms should be positive and significant.

\section{TABLE 2 \\ PREDICTING THE Ind-ID WITH ORIGINAL MODEL (LEFT) AND MODEL INCLUDING INTERACTIONS OF NEWS INTEREST}

\begin{tabular}{lcc}
\hline & Original Model & News Interests Interactions \\
\hline Distance to Rep & $-0.079^{*}$ & 0.110 \\
& $(0.044)$ & $(0.129)$ \\
Rep Match & $0.106^{* * *}$ & $0.185^{* * *}$ \\
& $(0.024)$ & $(0.071)$ \\
Distance to Sen1 & $-0.794^{* * *}$ & $-0.758^{* * *}$ \\
& $(0.040)$ & $(0.121)$ \\
Sen 1 Match & -0.548 & $-0.472^{* * *}$ \\
& $(0.022)$ & $(0.067)$ \\
\hline
\end{tabular}




\begin{tabular}{lcc}
\hline Distance to Sen2 & $-0.785^{* * *}$ & -0.611888 \\
Sen2 Match & $(0.040)$ & $(0.123)$ \\
& $-0.560^{* * *}$ & $-0.381^{* * *}$ \\
News Interest & $(0.022)$ & $(0.068)$ \\
& $-0.600^{* * *}$ & -0.164 \\
Basic Rep Int. & $(0.013)$ & $(0.127)$ \\
& $-0.580^{* * *}$ & 0.359 \\
Basic Sen 1 Int & $(0.045)$ & $(0.140)$ \\
& $1.115^{* * *}$ & $0.887 * * *$ \\
Basic Sen 2 Int & $(0.043)$ & $(0.134)$ \\
& $1.193^{* * *}$ & $0.959^{* * *}$ \\
Rep News Int & $(0.043)$ & $(0.136)$ \\
& & 0.350 \\
Sen1 News Int & & $(0.216)$ \\
Sen2 News Int & & $0.365^{*}$ \\
Constant & & $(0.208)$ \\
& & $0.421 * * *$ \\
Observations & $0.542^{* * *}$ & $(0.210)$ \\
Log Likelihood & $(0.074)$ & $0.274 * *$ \\
Akaike Inf. Crit. & 306,193 & $(0.108)$ \\
\hline Note: & $-179,488.500$ & 306,193 \\
& $359,938.900$ & $-179,469.900$ \\
& & $359,919.800$ \\
\hline
\end{tabular}

Not only is the fit of the model that includes news interest in the interactions a slightly better fit for the data (it has a lower AIC), but also it provides modest evidence that following the news moderates the relationship between distance and independent-identity. That is, distance is more predictive of independentidentity for respondents who follow the news more often than it is for respondents who follow the news less often. This result at least does not refute my proposed mechanism linking distance to independentidentity, however an over-time analysis will be necessary to make definitive statements about causality and mechanisms.

\section{Interpreting Results}

When dealing with a generalized linear model (including a probit model) that uses interaction terms, one safe way to assess a hypothesis is to create a set of hypothetical respondents who have mean values for all control variables and who vary only according to explanatory variables relevant to one's hypothesis. Then, you ask the model to make estimates as a function of the stylized variation in your variables of interest (Berry, DeMeritt, \& Esarey, 2009). I use the distribution function of the normal distribution to transform estimates generated by the model into predicted probabilities, and I display those predicted probabilities (with 95\% confidence intervals) as a function of movements in each distance variable (and all distance variables moving together) in Figure 6 below. Since my hypothesis concerns only those coded as "matched" for my dummy variables, all hypothetical observations portrayed below are coded " 1 " for all three match variables. 


\section{FIGURE 6 \\ HOW CHANGES IN DISTANCES AFFECT PREDICTED PROBABILITIES OF Ind-ID}
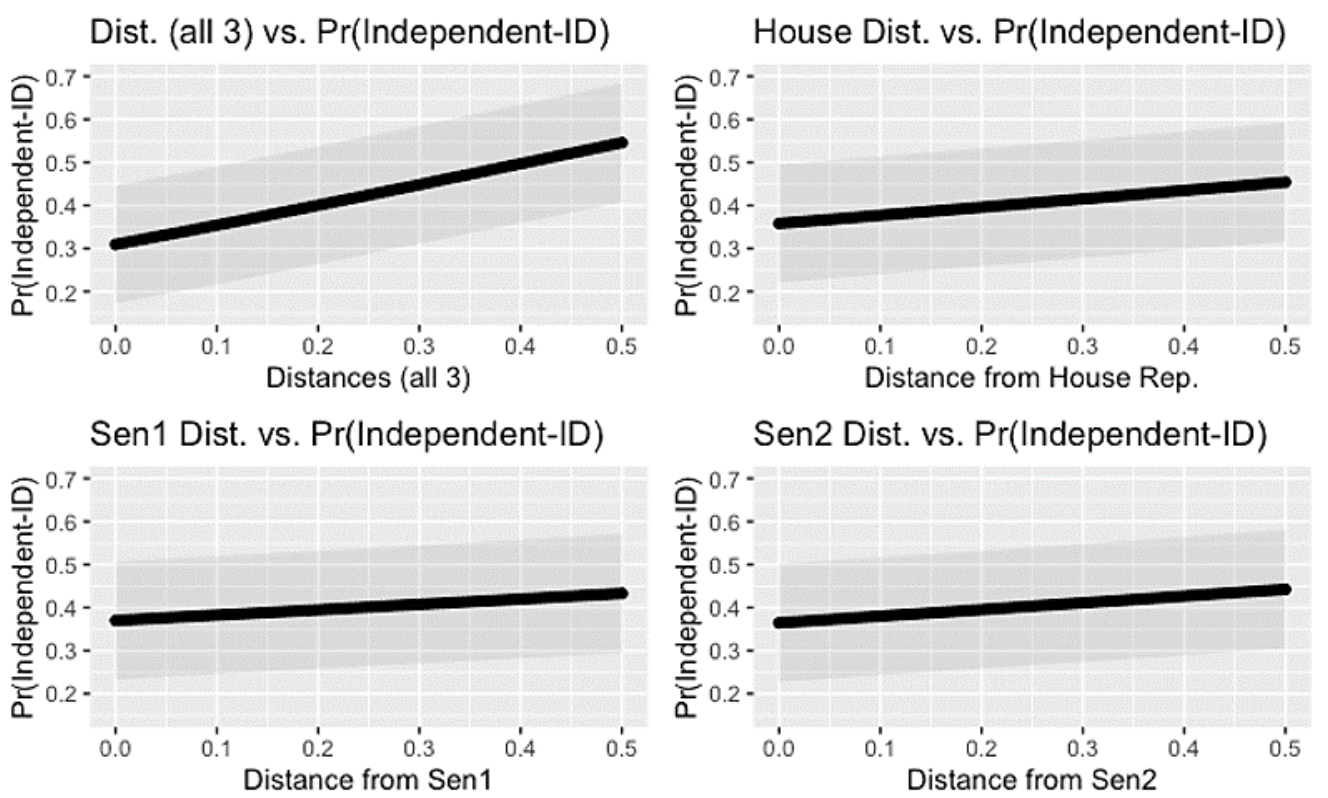

Note: Only matched respondents included

While each plot appears to display a straight line, the plots actually display roughly straight portions near the middle of the of the cumulative distribution function of the standard normal distribution. These plots show that, if a respondent is ideologically matched to her $\mathrm{MC}$, increased distance from that $\mathrm{MC}$ is always predicted by the model to be associated with an increased predicted probability that the respondent self-identifies as an independent. On the other hand, the wide confidence intervals show that we cannot be confident in any of the relationships between distance variables and independent-identity suggested by the positive slope of the trend lines. In fact, confusion matrices for the full model and the model including only control variables and no distance or match variables show that the two models are similarly successful at predicting accurate values for independent-identity. Thus, I am not comfortable rejecting the null hypothesis and for now conclude that there is no meaningful association between distance and independent-identity.

\section{DISCUSSION}

This paper concludes that one's ideological distance from one's House Representative and Senators is positively associated with one's probability of describing oneself as an Independent. Further, this paper finds that this positive association is moderated by the extent to which one follows the news. That is, those who follow the news very consistently on average have a better idea of who represents them and where those representative stands relative to the respondents themselves, and this knowledge allows for the application of the availability heuristic as I propose in an earlier section.

Three potential advancements could significantly strengthen a subsequent version of this paper. First, one could apply panel data to test this paper's hypothesis and proposed mechanism on individuals surveyed multiple times. Such an analysis could identify a sample of respondents who experienced a change in partisan-identity that overlapped with a change in representation, then regression analysis could be used to test whether those changes in representation appear to cause the changes in partisan-identity.

Second, respondents' ideologies could be measured based on their policy preferences rather than their self-described ideology. This would lead to a much more granular measure of respondents' ideologies, thus mitigating the lumpiness of the distribution of my distance measure. Since this lumpiness violates assumptions of normality, such a change may be preferable. To the contrary, however, it is possible that 
my coarser method is more appropriate for this project because insofar as respondents compute distances in order to make self-identification- or voting-decisions, they are more likely to consult their self-evaluated ideology than to consult some metric favored by political scientists.

Third, if my hypotheses are true in the United States, they should be true anywhere where negative partisan affect is present. Further, the size of the effect I hypothesize should vary as a function of the extent of this partisan affect. Where there is more negative partisan affect, I expect a greater impact of distance on independent-identity (and vice versa).

\section{REFERENCES}

Ahler, D.J., \& Sood, G. (2018). The parties in our heads: Misperceptions about party composition and their consequences. The Journal of Politics, 80(3), 964-981.

Annenberg Public Policy Center of the University of Pennsylvania. (2014). Percentage of Independent voters grew significantly, study shows. Retrieved from https://www.annenbergpublicpolicycenter.org/percentage-of-independent-voters-grewsignificantly-study-shows/

Ansolabehere, S., Snyder, J.M., Jr., \& Stewart, C., III. (2001). Candidate Positioning in U.S. House Elections. American Journal of Political Science, 45(1), 135-59.

Berry, W.D., DeMeritt, J.H.R., \& Esarey, J. (2009). Testing for Interaction in Binary Logit and Probit Models: Is a Product Term Essential. American Journal of Political Science, 54(1), 248-266.

Campbell, A., Converse, P., Miller, W., \& Stokes, D.E. (1960). The American Voter. New York: John Wiley \& Sons, Inc.

Downs, A. (1957). An Economic Theory of Democracy. New York: Harper and Row.

Edwards, A. (1953). The relationship between the judged desirability of a trait and the probability that the trait will be endorsed. Journal of Applied Psychology, 37(2), 90-93.

Green, D., Palmquist, B., \& Schickler, E. (2002). Partisan hearts and minds. New Haven: Yale University Press.

Greene, S. (1999). Understanding party identification: A social identity approach. Political Psychology, 20(2), 393-403.

Hill, S.J., \& Tausanovitch, C. (2015). A disconnect in representation? Comparison of trends in congressional and public polarization. The Journal of Politics, 77(4), 1058-1075.

Iyengar, S., Sood, G., \& Lelkes, Y. (2012). Affect, not ideology: A social identity perspective on polarization. Public Opinion Quarterly, 76(3), 405-431.

Iyengar, S., \& Westwood, S.J. (2015). Fear and loathing across party lines: New evidence on group polarization. American Journal of Political Science, 59(3), 690-707.

Iyengar, S., Lelkes, Y., Levendusky, M., Malhotra, N., \& Westwood, S.J. (2019). The origins and consequences of affective polarization in the United States. Annual Review of Political Science, 22, 129-146.

Klar, S., \& Krupnikov, Y. (2016). Independent Politics: How American Disdain for Parties Leads to Political Inaction. New York: Cambridge University Press.

Kuriwaki, S. (2018). Cumulative CCES Common Content (2006-2017). Retrieved from https://dataverse.harvard.edu/dataset.xhtml?persistentId=doi:10.7910/DVN/II2DB6

Lee, D.S., Moretti, E., \& Butler, M.J. (2004). Do Voters Affect or Elect Policies? Evidence for the U.S. House. Quarterly Journal of Economics, 119(3), 807-59.

Levendusky, M., \& Malhotra, N. (2015). (Mis) perceptions of partisan polarization in the American public. Public Opinion Quarterly, 80(S1), 378-391.

Lewis, J.B., Poole, K., Rosenthal, H., Boche, A., Rudkin, A., \& Sonnet, L. (2021). Voteview: Congressional Roll-Call Votes Database. Retrieved from https://voteview.com/

Pew Research Center: U.S. Politics \& Policy. (2019). Political Independents: Who They Are, What They Think. Retrieved from https://www.pewresearch.org/politics/2019/03/14/political-independentswho-they-are-what-they-think/

70 Journal of Management Policy and Practice Vol. 22(2) 2021 
Poole, K.T., \& Rosenthal, H. (1985). A Spatial Model for Legislative Roll Call Analysis. American Political Science Review, 29(2), 257-384.

Poole, K.T., \& Rosenthal, H. (2011). Ideology and congress (Vol. 1). Piscataway, NJ: Transaction Publishers.

Poole, K.T. (2005). Spatial models of parliamentary voting. Cambridge, UK: Cambridge University Press.

Tajfel, H., \& Turner, J.C. (1979). An integrative theory of intergroup conflict. The Social Psychology of Intergroup Relations, 33(47), 33-37.

Tversky, A., \& Kahneman, D. (1974). Judgment under Uncertainty: Heuristics and Biases. Science, 185(4157), 1124-1131.

Twenge, J.M., Honeycutt, N., Prislin, R., \& Sherman, R.A. (2016). More Polarized but More Independent: Political Party Identification and Ideological Self-Categorization Among U.S. Adults, College Students, and Late Adolescents, 1970-2015. Personality and Social Psychology Bulletin, 42(10), 1364-1383.

Zaller, J. (1992). The nature and origins of mass opinion. Cambridge, UK: Cambridge University Press.

\section{APPENDIX}

\section{Missing Data}

Five variables used in my model display significant missingness (over $2 \%$ of respondents have missing data for these variables), and some other variables display minor missingness (less than $1 \%$ of the sample is missing data for these variables). By default, the programming software $\mathrm{R}$ used for regression analysis for this project uses "listwise deletion" as the technique for handling missingness. This technique simply omits all observations from its analysis that have a missing value for any variable in the model. Regressions not included here but available from the author show that all results discussed in this paper are robust to any popular handlings of missingness including median-imputed missing values, mean-imputed missing values, mode-imputed missing values for categorical variables, and listwise deletion. 